OPEN ACCESS

Edited by:

Ryuji Kaji,

University of Tokushima, Japan

Reviewed by:

Graziella Madeo,

University of Rome Tor Vergata, Italy

Mario Treviño Villegas,

Instituto de Neurociencias

Universidad de Guadalajara, Mexico

*Correspondence:

Penelope Hannant penny.hannant@coventry.ac.uk; Sarah Cassidy

sarah.cassidy@coventry.ac.uk

Specialty section:

This article was submitted to

Movement Disorders,

a section of the journal

Frontiers in Neurology

Received: 16 March 2016

Accepted: 25 July 2016

Published: 10 August 2016

Citation:

Hannant P, Tavassoli T and

Cassidy S (2016) The Role of

Sensorimotor Difficulties in

Autism Spectrum Conditions.

Front. Neurol. 7:124.

doi: 10.3389/fneur.2016.00124

\section{The Role of Sensorimotor Difficulties in Autism Spectrum Conditions}

\author{
Penelope Hannant ${ }^{1 *}$, Teresa Tavassoli ${ }^{2}$ and Sarah Cassidy ${ }^{1,3,4 *}$ \\ ${ }^{1}$ Centre for Research in Psychology, Behaviour and Achievement, Coventry University, Coventry, UK, ${ }^{2}$ Seaver Autism Centre, \\ Icahn School of Medicine at Mount Sinai, New York, NY, USA, ${ }^{3}$ Autism Research Centre, University of Cambridge, \\ Cambridge, UK, ${ }^{4}$ Institute of Neuroscience, Newcastle University, Newcastle upon Tyne, UK
}

In addition to difficulties in social communication, current diagnostic criteria for autism spectrum conditions (ASC) also incorporate sensorimotor difficulties, repetitive motor movements, and atypical reactivity to sensory input (1). This paper explores whether sensorimotor difficulties are associated with the development and maintenance of symptoms in ASC. First, studies have shown difficulties coordinating sensory input into planning and executing movement effectively in ASC. Second, studies have shown associations between sensory reactivity and motor coordination with core ASC symptoms, suggesting these areas each strongly influence the development of social and communication skills. Third, studies have begun to demonstrate that sensorimotor difficulties in ASC could account for reduced social attention early in development, with a cascading effect on later social, communicative and emotional development. These results suggest that sensorimotor difficulties not only contribute to non-social difficulties such as narrow circumscribed interests, but also to the development of social behaviors such as effectively coordinating eye contact with speech and gesture, interpreting others' behavior, and responding appropriately. Further research is needed to explore the link between sensory and motor difficulties in ASC and their contribution to the development and maintenance of ASC.

Keywords: autism spectrum conditions, sensory, motor, sensorimotor, repetitive behavior, cerebellum, gamma-aminobutyric acid, social cognition

\section{INTRODUCTION}

Successful social functioning requires multiple skills, such as quickly seeking out and integrating information from pertinent social cues in order to plan and carry out an appropriate response. This involves effectively coordinating non-verbal and verbal language including posture, vocaltone, facial gesture, and eye contact with speech during a social interchange. Hence, social reciprocity requires integrating a variety of sensory information from the environment to plan and execute movement effectively. If this ability was impaired, we could predict a whole host of difficulties, from performing simple actions (such as reaching for a cup) to having difficulty seeking out pertinent social cues and even difficulties interpreting others' behavior and responding appropriately. Furthermore, novel and challenging actions may be avoided and known perfected routines preferred.

Abbreviations: ASC, autistic spectrum conditions; GABA, gamma-aminobutyric acid. 
Current DSM-5 criteria (1) refers to Autism as a "disorder," however in this paper, we use the less stigmatizing term "condition," recognizing that Autism includes both strengths and weaknesses, while still being a medical condition for which individuals need support. Individuals with Autism Spectrum Conditions (ASC) have difficulties with social interaction and communication, repetitive behaviors, narrow circumscribed interests, and atypical sensitivity to sensory information (1). Three decades of research have attempted to uncover the cause of this diverse range of difficulties in ASC with little success. Thus some researchers have suggested that it is time to give up on finding a single unifying theory of ASC, as it may rather consist of a number of co-occurring, genetically distinct clusters of symptoms (2-4). Progress may have been hampered by lack of research into the non-social difficulties seen in ASC; repetitive behaviors, narrow circumscribed interests, and sensory difficulties. However more recent research, such as that by Gowen and Hamilton (5), has started to explore the contribution of sensorimotor difficulties (defined as an impairment in the pathway involving motor activity triggered by sensory stimuli) to the development and maintenance of ASC. This could provide a more parsimonious explanation (compared to multi-deficit accounts) of the social and non-social difficulties that come to develop in ASC. By examining both psychological and biological evidence, this paper therefore explores and hypothesises that motor coordination and sensory difficulties in ASC may be associated with the development and maintenance of ASC symptoms.

\section{MOTOR COORDINATION IN AUTISM SPECTRUM CONDITIONS}

Unusual motor processing is associated with ASC. Initial clinical reports of ASC reported general "clumsiness" in these individuals (6-9), and this has been corroborated in more recent research (10-15). Furthermore, Fournier et al. completed a robust meta-analysis including 51 comparisons of motor ability and deduced that individuals with ASC display a pronounced motor impairment compared to neuro-typical controls, with their motor skills often fall 1.5 SDs below the typical mean (16). Green et al. (12) and Miyahara et al. (17) were able to quantify the prevalence of motor impairment by administering assessments of coordination to children with ASC, concluding that approximately $80 \%$ had definite motor impairment with $10 \%$ being borderline. The prevalence of impaired motor processing in coordination, praxis, balance, and muscle tone in ASC is also echoed in a range of other studies (5, 18-21). More narrowly, Ming, Brimacombe, and Wagner went on to identify the prevalence of specific deficits in motor skills, with hypotonia (low muscle tone) and apraxia (impaired ability to execute planned movement) being the most common deficit (51 and 34\%, respectively). Additionally, a review written by Gowen and Hamilton (5) demonstrated how a number of fine and gross motor movements had been identified and reported, such as: slower repetitive hand and foot movement, slower and less accurate manual dexterity, poorer ball skills (e.g., aiming and catching), unstable balance, impaired gait (e.g., tandem gait, heel, or toe walking), reduced coordination of locomotor skills (e.g., running and jumping), and hypotonia.

Motor abnormalities in ASC are present from early infancy (22-24), such as head lag in infants (defined as the head lagging behind the trunk in a pull-to-sit position) (25). Motor delays are significantly more likely to be reported by parents as the first area of concern at a mean age of 14.7 months (26). However, Teitelbaum et al. (22) also described, in detail, coordination differences between babies with and without ASC from as young as 6 months old, such as persistent asymmetry when lying and early impairments in rolling over from back to stomach.

\section{SENSORY REACTIVITY IN AUTISM SPECTRUM CONDITIONS}

Atypical sensory reactivity, as defined here as the psychological reaction that occurs when a person is exposed to sensory stimuli, is also associated with ASC. Pioneering reports of ASC described sensory "intrusions" $(6,7)$. Studies corroborate these initial clinical descriptions, showing that the prevalence of sensory reactivity problems in ASC is high. Caminha and Lampreia (27) reported a $69-80 \%$ occurrence of sensory dysfunction symptoms in ASC, while (28) noted that 95\% of their sample had some degree of sensory processing difficulties. Findings from sensory symptoms in ASC, such as hypersensitivity and hyposensitivity, vary depending on modality tested, level of analysis, and method used. Research has, for example, shown the existence of basic sensory reactivity symptoms such as: hypersensitivity across visual (29), tactile (30-32), auditory (33-36) and olfactory (37) domains as well as hyposensitivity to olfactory and gustatory stimuli $(38,39)$; differences in perceptual function (40); and proprioceptive impairment (ability to determine where the body is in space) $(41,42)$.

More narrowly with respect to visual processing, although visual acuity seems to be typical in individuals with ASC $(43,44,45)$, children with ASC statistically; (a) score higher on the Embedded Figures test, thereby demonstrating greater field independence, or the ability to see objects as discrete and distinct from their background as opposed to central coherence $(46,47)$; (b) exhibit faster visual search times $(47,48)$, have enhanced discrimination ability (48); and (c) detect more unattended changes in natural stimuli when compared to typical developing children (49). Such findings of an apparent superior performance in basic sensory perception led Mottron et al. (50) to suggest that individuals with ASC have "enhanced perceptual functioning" (51). There is however evidence to demonstrate diminished performance on higher order visual processing tasks such as visual spatial and visual motion processing (52-54). Some studies have indicated that adults with ASC are impaired at motion processing but retain intact form processing (perhaps reflecting selective dysfunction of the magnocellular pathway - the motion processing pathway) $(52,54-56)$. Other studies have found atypical visual global processing within the dorsal visual pathway (57), or have found that attentional and cognitive demands of the tasks might contribute to differing results (58). For a comprehensive review of vision in ASC, see Ref. (53). Taken together, basic early stage 
visual processing seems to be similar to or superior in individuals with ASC; however, there appears to be compromised higher order visual processing, which could be linked to difficulties with temporal sensorimotor skills, such as motion processing.

Regarding auditory processing, findings are similar in nature with intact or enhanced basic auditory perception and potential difficulties with processing higher order complex sounds. For example, individuals with ASC show superior pitch processing $(55,59,60)$. O'Riordan and Passetti (61) also report greater auditory discrimination ability in children with ASC, and JärvinenPasley et al. (62) show superior perceptual processing of speech in children with ASC. However individuals with ASC also show difficulties in filtering complex auditory sound such as speech from background noise and therefore can often have difficulty attending to or registering auditory information $(63,64)$.

In tactile processing results have also been mixed, showing hypersensitivity $(31,65,66)$ to basic stimuli, as well as no differences (61). Another line of research shows differences in adaptation toward touch; Tommerdahl et al. (66) showed that participants with ASC outperformed controls in tactile acuity after short adaptation to a vibrotactile stimulus period of $0.5 \mathrm{~s}$. In addition, they demonstrated that individuals with ASC do not show enhanced spatial localization after being adapted to tactile stimulus, which occurs in typical controls. A more recent study also showed differences in tactile processing in children and adults with ASC (67). Differences in auditory and tactile processing might be associated with sensorimotor difficulties in ASC as well as visual differences.

The chemical senses have been investigated less than other senses, showing mostly impaired or intact processing in ASC depending on measure used $(38,39)$. Suzuki et al. (39) for example, reported impaired odor identification using the University of Pennsylvania Smell Identification Test in adults with ASC. A second study by Bennetto et al. (38) reported that adolescents (10-18 years) with ASC were less accurate in olfactory identification. However olfactory detection thresholds seem to be intact in individuals with ASC $(39,68)$. Regarding taste processing, identification seems to be impaired in individuals with ASC. Bennetto et al. (38) found that adolescence with ASC are less accurate in identifying sour and bitter tastes but showed similar identification for sweet and salty tastes. In line with this, Tavassoli and Baron-Cohen (68) found that adults with ASC had difficulties in identifying bitter, sour, and sweet tastes. Moreover, on sensory questionnaires, individuals with ASC are reported to show more olfaction and taste sensitivity compared to individuals without ASC (28, 69-72). Individuals with ASC (55\%) for example present with more clinical symptoms in smell/taste sensitivity on the Short Sensory Profile compared to children with Sensory Processing Disorder (32\%) (73).

Kern et al. (74) reported that abnormal responsivity in each of the main sensory modalities (auditory, visual, touch, and oral) was not independent, showing significant correlations between them; suggesting that sensory responsivity dysfunction in ASC is global in nature. This is further supported by the recognition of increased rates of synesthesia in ASC (a condition in which a sensation in one sensory modality triggers a perception in another) (75). Additionally, a study by Stevenson et al. (76) recently demonstrated reduced multisensory integration [described as the process whereby information from all the different sensory modalities are combined to influence perception, decision and behavior (77)] in ASC, by using a sound-induced flash illusion as a measure. However, sensory abnormalities in ASC appear to have the potential to reduce with age: a cross-sectional, linear regression analysis with 104 participants, aged 3-56 years, suggested that sensory difficulties become similar to typical controls by the age of 33 years (78). A meta-analysis also showed that sensory symptoms seem to be most prevalent between the ages of 6-9 years of age (79).

\section{IMPACT OF MOTOR COORDINATION AND SENSORY REACTIVITY IN ASC}

Difficulties in motor coordination and sensory reactivity have both separately been associated with the severity of symptoms in ASC. Research and primary observations indicate that the range of motor difficulties experienced by children with ASC appear to affect the development and maintenance of their social and communicative difficulties. Examples of this include the significant impairments shown by children with ASC in skilled motor gestures, including imitation (80) and development of speech sound production (20). Children with motor coordination difficulties are less competent at recognizing emotions in others (81) and are more likely to have increased anxiety on the playground due reduced social interaction (24). Furthermore, research has shown a correlation between motor and praxis performance and social communication skills in ASC (82-87). Piek and Dyck expands on the correlation and long recognized comorbidity of Developmental Coordination Disorders (DCD) and ASC, suggesting that as the disorders typically occur together, they either have overlapping causes or that one disorder is a direct cause of the other (88). However, research also suggests that impairments in movement could be a fundamental cause of the social and communicative difficulties seen in ASC, as opposed to a peripheral feature of the condition [see Ref. (89)]. This theory is consistent with recent evidence that suggests children who display fine motor difficulties early in childhood (from 7 months old) are significantly more at risk of developing an ASC by 36 months (90). Cross syndrome studies have also shown that children with ASC have more difficulties in basic (91) and gestural motor skills (92) compared to children with Attention-Deficit Hyperactivity Disorder (ADHD) and/or DCD. These results suggest that early motor difficulties are associated with the development of social and communicative difficulties later in life. Accordingly, as autism severity is based on social communication impairments in current DSM-5 criteria (1), this may be of paramount importance in the development of ASC.

In addition to the challenging sensory hypersensitivity/overload and hyposensitivity experienced by individuals with ASC, research has also linked sensory reactivity disorders to social communication difficulties $(85,93,94)$. Fitzgibbon et al. (95) proposed that both physical pain and social pain are processed atypically in individuals with ASC and insensitivity to pain, for example, could in turn limit empathy and understanding of pain in others. Recent research has also identified associations 
between sensory reactivity and the severity of autism such as Tavassoli et al. (33) who reported that autistic traits defined by the Autism Spectrum Quotient, correlated positively with sensory over-responsivity, and Boyd et al. (96) specifically noted high levels of hyper responsive behavior predicted high levels of repetitive behavior. Other such studies include: Ashwin et al. (37), Kern et al. (74), Hilton et al. (85), Ben-Sasson et al. (79), Lane et al. (97), Siaperas et al. (98), and Tavassoli et al. (99).

\section{SENSORIMOTOR INTEGRATION IN ASC}

The evidence reviewed so far show that sensory and motor difficulties are prevalent in ASC and impact on social functioning (86, 93). Evidence also suggests that these difficulties are present from birth, e.g., pre-social skill deficits $(29,100)$, and increase the risk of developing ASC by aged 3 years (90). This indicates that there is a possible impairment in the process of sensorimotor integration [a brain process that allows, by complex neural operations, the connection of the sensory and motor domains (101), p. 427] that plays a fundamental role in the development of ASC. Although further studies are needed to explore whether sensorimotor integration difficulties are unique to ASC, Gowen and Hamilton (5) also proposed that altered sensory input and variability in motor execution "together" may play a pivotal role in ASC. Researchers have linked weaker praxis and motor performance to sensory reactivity in ASC $(98,102-104)$. Additionally, Siaperas et al. (98) found that children with ASC demonstrated significant impairment in both motor performance and proprioceptive and vestibular processing and thus suggested that sensory difficulties are not a peripheral, but a core feature of ASC.

Sensory feedback and movement are intrinsically connected (105), as the ability to plan and execute a simple movement effectively (such as reaching for a cup), requires sensory feedback (such as your position in relation to the cup as you reach for it) in order to effectively coordinate movement while performing the action $(5,105)$. Any error signal (such as missing the cup) at the final stage of movement is then processed and corrected. As movements are repeated in this fashion, they become automatic, and the delay caused by continuous sensory feedback is reduced, as the motor command (feedforward program) rapidly generates a prediction of the sensory consequences of the action $(106,107)$. For this reason, when sensory guidance is unreliable, slow, or associated with negative effect, both the ability to first acquire a motor command, in addition to regulating a stored motor command, would be impaired, leading to limited accuracy and flexibility (105). Therefore, deficiencies in sensorimotor integration would present as difficulties in effectively utilizing sensory feedback to correct movements, resulting in coordination difficulties and sensory reactivity abnormalities comparable to those seen in ASC (100, 105-112).

A number of studies have shown difficulties in sensorimotor integration in ASC. For example, Ronconi et al. (113) demonstrated that visual attention was impaired in children due to an imbalance of sensorimotor feedforward and feedback programs, by demonstrating a slower zoom-in and zoom-out mechanism in the eye. Schmitt et al. (114) and Mosconi et al. (115) demonstrated that those with ASC were significantly less accurate when moving their eyes from a central fixation to a peripheral target, showing increased saccade variability and difficulties in decelerating saccades. Wilkes et al. (116) also showed that children with ASC were delayed in initiating a saccade when following a moving light with their eyes compared to controls. Price et al. (117) demonstrated compromised visual sensitivity to human motion, and Glazebrook et al. (118) showed that adults with ASC had difficulty coordinating both hand and eye movements, taking significantly longer to complete integrated tasks than typical controls. These low level difficulties in initiating and adjusting saccades, and coordinating hand and eye movements, could explain a range of social and communication difficulties seen in ASC. For example, delay in looking to pertinent social cues (119-121), particularly for fast paced dynamic stimuli (122-125), with resulting difficulties in early social engagement and later ability to interpret others emotions and behavior $(122,123,126,127)$.

Studies have also shown that those with ASC have difficulty integrating sensory information in motor learning. For example, when children with ASC performed a motor learning task on a touch screen, the presence of a visual distractor did not impact their performance like with typical controls (109). Gepner suggested a correlation between visuo-postural detuning and ASC severity, whereby individuals with ASC had weaker postural stability and reactivity to environmental motion (128). Similarly, children with ASC are significantly less able to correct movements from visual compared to proprioceptive feedback (128-131). Studies have also shown difficulties specifically with motor movements, which require integrating visual cues or other sensory signals $(18,103,132)$, and children with ASC have difficulty specifically when tracing shapes using feedback from a mirror image, and imitating others actions (133). These results all suggest that those with ASC do not tend to incorporate other sensory inputs, particularly visual feedback, into motor learning and have difficulty coordinating visual and motor movements. These difficulties could particularly impact social learning from imitation and integration of eye movements with gesture during social communication in ASC. However, further research is needed to explore this possibility.

Despite the possible interpretations of perceptual feedback being incorrect, Vandenbroucke et al. (134), by using a forcedchoice texture segregation task, went on to suggest that with considerable practice individuals with ASC were able to compensate for the imbalance in feedback and build on a feedforward program. Larson et al. (135) also noted that the mechanisms of acquisition and adaptation of feedforward programs are indistinguishable between children with ASC and typically developing children. Furthermore, Gowen et al. (132) demonstrated that in comparison to neurotypical controls, individuals with ASC rely to a greater extent on a goal directed pathway, established in part by a feedforward program. Similarly, Rinehart et al. (136) demonstrated an intact ability to execute programed movement but atypical movement preparation. Nazarali et al. (137) demonstrated that individuals with ASC have difficulty reprograming already planned movements when given additional sensory information, and Glazebrook et al. (118) showed that individuals with ASC can use sensory input such as vision and proprioception, although the greater visual-proprioceptive integration required the more time 
was taken by the ASC group to perform the movements. Thus, with age, through continual practice, coping strategies and natural development, known, repetitive movements and feedforward motor programs appear to improve in ASC.

\section{BIOLOGICAL BASIS OF IMPAIRED SENSORIMOTOR INTEGRATION IN ASC}

In addition to psychological research given above linking sensorimotor integration to ASC, there is a substantial amount of biological evidence that collaborates this relationship. For example, difficulties in sensorimotor integration in ASC have been linked to the cerebellum, such as saccadic accuracy being connected to impairment of the error-reducing function of the cerebellum (114). Other examples include a correlation in the magnitude of cerebellar hypoplasia with decreased exploration in children with ASC (138), and an association of cerebellum volume with specific difficulties incorporating visual cues in motor learning (129). The cerebellum is reported to contain pathways that link sensory signals to motor areas in the brain (139), and these are important in controlling and coordinating movement (140). Stoodley and Schmahmann (141) specifically showed an anterior sensori-motor versus posterior cognitive/emotional dichotomy in the cerebellum. Research has also shown that the cerebellum has a fundamental role in maintaining the equilibrium between feedback and feedforward programs in sensorimotor integration, for example, Kawato et al. (142) found that the cerebellum was the most likely site for feedforward programs to be stored, by using functional magnetic resonance imaging (fMRI) to measure specific brain activity during coordinated and planned movement; Brooks (105) and Mostofsky et al. (143) noted that the cerebellum was responsible for triggering learned movement (feedforward programs); and Fuentes and Bastian (144) suggested that the cerebellum is intrinsic to predicting movement outcomes.

Abnormalities in the cerebellum of individuals with ASC are one of the most consistent neuroanatomical findings (145). McAlonan et al. (146) found structural abnormalities in the cerebellum with deficits in gray and subcortical white matter. Using fMRI, atypical patterns of both cerebral activation (indirectly detected by increased cerebral blood flow) and deactivation (signaled by decreased cerebral blood flow) have been noted in ASC: where cerebral activations during a simple motor movement were found to be mainly confined to the anterior cerebellum in TD adults but also spread to the posterior cerebellum in ASC adults (147-149). Additionally, 95\% of autistic cerebella examined at autopsy showed clearly defined anatomic abnormalities; most commonly a significantly decreased number of Purkinje cells, a large inhibitory neuron thought to regulate motor function $(145,150,151)$.

Moreover, the basal ganglia, which is considered to be reciprocally connected to the cerebellum (152), is also reputed to play a functional role in both motor and sensory control and integration $(152,153)$. More specifically, it is hypothesized that within the basal ganglia, there are two distinct striatal pathways that facilitate both movement and sensory representation. Although it is unclear whether these are distinct or seemingly intertwined (154), a direct pathway appears to be responsible for facilitating movement whereas an indirect pathway is thought to inhibit both competing motor programs and afford sensory control by filtering and gating sensory input (155). The basal ganglia have been shown to have decreased volume in ASC (156). Furthermore, the striatum, one of the largest components of the basal ganglia, is reported as having excess functional connectivity in ASC (157).

In addition to anatomical differences of the cerebellum and basal ganglia being associated with sensorimotor impairment in ASC, both brain regions contain large GABAergic inhibitory neurones. More specifically, Purkinje cells, considered the sole output of all motor coordination in the cerebellar cortex (158) and "medium spiny neurons," thought to form 95\% of the striatum in the basal ganglia (159). The inhibitory neurotransmitter GABA (gamma-aminobutyric acid) and the main excitatory neurotransmitter glutamate released by these neurones also play an important role in sensory discrimination in ASC (160). GABA is known to decrease the firing of neurons (161), thereby reducing and inhibiting sensory feedback. Alterations in GABAergic transmission have been associated with sleep disorders (melatonin production) (162), mood disorders, anxiety and other hyperexcitable states such as epilepsy $(163,164)$. GABA levels have also been shown to be lower in the auditory and motor cortices of children with ASC with a mean deficiency of GABA equating to 22 and $11 \%$, respectively, in comparison to TD peers (165) GABAergic functioning has been implicated in tactile reactivity $(166,167)$. Moreover, reductions in GABAergic system have been discovered in ASC brain tissue: with significant reductions in $\mathrm{GABA}_{\mathrm{A}}$ receptors, $63 \%$ reduction in comparison to controls (168), and a reduction by $61 \%$ of the glutamic acid decarboxylase protein (the enzyme responsible for converting glutamate into GABA) (169). Similarly, increased glutamate levels (excitatory neurotransmitter) in blood and platelets have been found in ASC subjects, suggesting impaired conversion of glutamate to GABA, consequently increasing the excitatory state of the brain $(169,170)$. A GABA receptor gene, GABRB3, is one of the key candidate genes for ASC as found in humans as well as in animal models $(171,172)$. A study by Green et al. (173) demonstrated that participants with ASC also showed stronger activation of the amygdala toward sensory stimuli, which is thought to perform a pivotal role in emotion processing and decision-making; GABAergic neurons are also present in the amygdala.

Further evidence of an imbalance in these vital neurotransmitters in ASC arise from treatments for hyperactive disorders of the auditory system, such as tinnitus and hyperacusis (a lowered threshold for discomfort from sounds that typical individuals do not find unpleasant) (174), where the administration of benzodiazepines such as Clonazepam (an allosteric modulator of the $\mathrm{GABA}_{\mathrm{A}}$ receptor) have been used to restore the balance between inhibition and excitation in the brain (174). Banji et al. (175) also demonstrated that induced cerebellar damage in mice instigated motor clumsiness, similar to that seen in ASC, the motor clumsiness was then reduced by treating the mice with green tea extract (Camellia sinensis). L-Theanine is a major amino acid component found almost exclusively in green tea (176-178) and blocks the binding of L-glutamic acid 
to glutamate receptors in the brain $(176,178,179)$, thereby perhaps aiding the improvement in motor activity by increasing inhibition of movement.

\section{IMPACT OF SENSORIMOTOR DIFFICULTIES IN ASC}

Further evidence to support our hypothesis can be found in studies that have demonstrated sensorimotor difficulties and associated biological markers specific to ASC. In particular, difficulties with accuracy, speed, and initiation of eye movements; coordination of eye and body movements; and the ability to integrate visual information into motor learning could all have a profound impact on social learning opportunities during development and maintenance of social and communication difficulties in ASC. For example, difficulty quickly moving and correcting saccades could explain the well-established lack of attention to social cues in young children who go onto develop ASC $(180,181)$, with a cascading effect on later social development and learning (124). Difficulties integrating eye movements with body movements could account for social communication and interaction difficulties in ASC such as integrating eye contact with gesture and speech (1). Difficulties integrating other cues, particularly visual information in motor learning, could explain the challenges faced in social imitation in ASC [e.g., Ref. (182)]. Social imitation is key for social learning and could also contribute to the development and maintenance of social difficulties in ASC. Sensorimotor impairment could also explain other autistic traits such as echolalia and repetitive behaviors. A major study in brain anatomy using MRI by McAlonan et al. put forward that the impaired inhibition of sensory feedback through defective sensory gating (the brain's selective processing of sensory stimuli) found in ASC, could lead to difficulties where the individual is unable to inhibit repetitive thoughts, actions, or speech (146). Indeed, non-ASC related research has already demonstrated links between sensorimotor control and social behavior. Skewes et al. (183), by noting how the size and precision of a visual illusion may influence visual motor behavior, suggest that potentially, the way in which sensorimotor control adapts to the opinions of others may help facilitate smoother social interaction. Hoke et al. (184) identified that the integration of sensory and motor processing underlies social behavior in tungara frogs.

A number of theories have attempted to explain the development of ASC, including ability to understand mental states to predict others behavior (Theory of Mind) (185); impaired eye gaze detection (186) or lack of early social attention in favor of objects (124). These theories have failed to explain the wide range of difficulties seen in ASC from social communication to sensory reactivity and repetitive motor movements. Sensory and motor difficulties have also been considered largely peripheral to ASC, with atypical sensory reactivity only recently being added to DSM-5 diagnostic criteria (1). However, the wide range of difficulties in ASC could be explained by using a wider perspective: a central theory of sensorimotor integration impairment and the ensuing "chain" of likely misalignments and misjudgments that follow. Early development theories such as Jean Piaget's developmental stage theory proposed that sensorimotor integration was central to neurotypical development and where a child struggles to coordinate their initial sensory experiences, further stages of development will be impaired (187).

\section{FUTURE DIRECTIONS}

To the authors' knowledge, there are no studies that have explored the impact of sensorimotor difficulties (such as saccades or impaired motor learning) on the development or maintenance of core ASC symptoms. Sensory feedback and feedforward programs are seemingly pivotal to successful sensorimotor integration. A greater understanding of these systems and the impact of sensorimotor integration in ASC may be a crucial way forward to understanding the development and maintenance of this condition. For example, research that identifies a significant correlation between motor coordination, sensory reactivity, and the severity of ASC could demonstrate that these are fundamental and pervasive difficulties associated with and reflective of the scale of the condition. Similarly, further research into the varying degrees of sensorimotor difficulties and more specifically at the level the difficulties occur, such as the more complex higher order level including anticipation and timing, may also be crucial in identifying if and which area the sensorimotor chain is affected in ASC. There also appears to be a critical window for the impact of such sensorimotor deficits on cognitive and social development: below the age of two. Consequently, interventions incorporating both structured physical tasks and sensory environments below this age should have particular focus. Such intervention is also recommended in Barenek's review of the efficacy of sensory and motor interventions in ASC (2002), where it is noted converging evidence would suggest beginning sensorimotor inventions at an early age may be beneficial. Similarly, sensorimotor integration difficulties in comorbid conditions, such as dyslexia and dyscalculia should also be explored, as finding a recurrent thread to specific learning difficulties in ASC could alter the type and time of intervention.

Additionally, the apparent deficiency of the inhibitory neurotransmitter GABA in the cerebellum of ASC individuals should also be an area for consideration, as this could have a global impact on sensorimotor planning, cognitive and social development. The introduction of a non-evasive GABA substitute, such as oolong tea, could therefore lead to a decrease in sensory feedback, supporting an equilibrium with feedforward programing and ultimately moderate planned movement.

\section{CONCLUSION}

To conclude, we hypothesize that social communication, interaction difficulties, and repetitive behaviors in ASC appear to be associated with motor coordination and sensory reactivity, specifically attaining and coordinating the delicate balance between the feedforward programs and feedback systems of sensorimotor integration. However, once reached, research indicates that in comparison to controls, the feedforward program can be maintained and utilized just as efficiently in ASC provided environmental cues stay the same. Such conclusions are reinforced when 
listening to the lived experiences of ASC individuals; "I can do buttons up fine, unless I concentrate too hard."

All studies included in this research have been summarized in Table S1 in Supplementary Material.

\section{AUTHOR CONTRIBUTIONS}

PH: developed topic, literature search, compiled evidence, wrote the manuscript, and completed the table. SC: literature search, compiled evidence, critical feedback, wrote the manuscript, and completed the table. TT: literature search, compiled evidence, critical feedback, and wrote the manuscript. All authors read and approved the final manuscript.

\section{REFERENCES}

1. American Psychiatric Association. Diagnostic and Statistical Manual of Mental Disorders. 5th ed. Washington, DC: Author (2013).

2. Happé F, Ronald A, Plomin R. Time to give up on a single explanation for autism. Nat Neurosci (2006) 9(10):1218-20. doi:10.1038/nn1770

3. Happé F, Ronald A. The 'fractionable autism triad': a review of evidence from behavioural, genetic, cognitive and neural research. Neuropsychol Rev (2008) 18(4):287-304. doi:10.1007/s11065-008-9076-8

4. Goodman R. Infantile autism: a syndrome of multiple primary deficits? J Autism Dev Disord (1989) 19(3):409-24.

5. Gowen E, Hamilton A. Motor abilities in autism: a review using a computational context. J Autism Dev Disord (2013) 43(2):323-44. doi:10.1007/ s10803-012-1574-0

6. Kanner L. Autistic disturbances of affective contact. Nervous child (1943) 2(3):217-50.

7. Asperger H. Die "Autistischen Psychopathen" im Kindesalter. Eur Arch Psychiatry Clin Neurosci (1944) 117(1):76-136.

8. DeMyer MK. Motor, perceptual-motor and intellectual disabilities of autistic children. Early Childhood Autism. Oxford: Pergamon Press (1976). p. 169-93.

9. Damasio AR, Maurer RG. A neurological model for childhood autism. Arch Neurol (1978) 35(12):777-86. doi:10.1001/archneur.1978.00500360001001

10. Berkeley SL, Zittel LL, Pitney LV, Nichols SE. Locomotor and object control skills of children diagnosed with autism. Adapt Phys Activ Q (2001) 18(4):405-16.

11. Mari M, Castiello U, Marks D, Marraffa C, Prior M. The reach-to-grasp movement in children with autism spectrum disorder. Philos Trans $R$ Soc Lond B Biol Sci (2003) 358(1430):393-403. doi:10.1098/rstb.2002.1205

12. Green D, Charman T, Pickles A, Chandler S, Loucas T, Simonoff E, et al. Impairmentinmovementskillsof childrenwithautisticspectrumdisorders. Dev Med Child Neurol (2009) 51(4):311-6. doi:10.1111/j.1469-8749.2008.03242.x

13. Hughes C. Brief report: planning problems in autism at the level of motor control. J Autism Dev Disord (1996) 26(1):99-107. doi:10.1007/BF02276237

14. MacNeil LK, Mostofsky SH. Specificity of dyspraxia in children with autism. Neuropsychology (2012) 26(2):165. doi:10.1037/a0026955

15. Staples KL, Reid G. Fundamental movement skills and autism spectrum disorders. J Autism Dev Disord (2010) 40(2):209-17. doi:10.1007/s10803-0090854-9

16. Fournier KA, Hass CJ, Naik SK, Lodha N, Cauraugh JH. Motor coordination in autism spectrum disorders: a synthesis and meta-analysis. J Autism Dev Disord (2010) 40(10):1227-40. doi:10.1007/s10803-010-0981-3

17. Miyahara M, Tsujii M, Hori M, Nakanishi K, Kageyama H, Sugiyama T. Brief report: motor incoordination in children with Asperger syndrome and learning disabilities. JAutism Dev Disord (1997) 27(5):595-603. doi:10.1023/A:1025834211548

18. Whyatt CP, Craig CM. Motor skills in children aged 7-10 years, diagnosed with autism spectrum disorder. J Autism Dev Disord (2012) 42(9):1799-809. doi:10.1007/s10803-011-1421-8

19. Ming X, Brimacombe M, Wagner GC. Prevalence of motor impairment in autism spectrum disorders. Brain Dev (2007) 29(9):565-70. doi:10.1016/j. braindev.2007.03.002

\section{FUNDING}

This work was funded by the Centre for Research in Psychology, Behaviour and Achievement, Coventry University, UK.

\section{SUPPLEMENTARY MATERIAL}

The Supplementary Material for this article can be found online at http://journal.frontiersin.org/article/10.3389/fneur.2016.00124

Table S1 | Summary of all studies included in the role of sensorimotor difficulties in the development of autistic spectrum conditions

Summary of demographics, methods and outcomes of all studies included in research.

20. Page J, Boucher J. Motor impairments in children with autistic disorder. Child Lang Teach Ther (1998) 14(3):233-59. doi:10.1191/ 026565998673400901

21. Kopp S, Beckung E, Gillberg C. Developmental coordination disorder and other motor control problems in girls with autism spectrum disorder and/or attention-deficit/hyperactivity disorder. Res Dev Disabil (2010) 31(2):350-61 doi:10.1016/j.ridd.2009.09.017

22. Teitelbaum P, Teitelbaum O, Nye J, Fryman J, Maurer RG. Movement analysis in infancy may be useful for early diagnosis of autism. Proc Natl Acad Sci U S A (1998) 95(23):13982-7. doi:10.1073/pnas.95.23.13982

23. Matson JL, Mahan S, Fodstad JC, Hess JA, Neal D. Motor skill abilities in toddlers with autistic disorder, pervasive developmental disorder-not otherwise specified, and atypical development. Res Autism Spectr Disord (2010) 4(3):444-9. doi:10.1016/j.rasd.2009.10.018

24. Bhat AN, Landa RJ, Galloway JCC. Current perspectives on motor functioning in infants, children, and adults with autism spectrum disorders. Phys Ther (2011) 91(7):1116-29. doi:10.2522/ptj.20100294

25. Flanagan JE, Landa R, Bhat A, Bauman M. Head lag in infants at risk for autism: a preliminary study. Am J Occup Ther (2012) 66(5):577-85. doi:10.5014/ajot.2012.004192

26. Chawarska K, Paul R, Klin A, Hannigen S, Dichtel LE, Volkmar F. Parental recognition of developmental problems in toddlers with autism spectrum disorders. J Autism Dev Disord (2007) 37(1):62-72. doi:10.1007/ s10803-006-0330-8

27. Caminha RC, Lampreia C. Findings on sensory deficits in autism: implications for understanding the disorder. Psychol Neurosci (2012) 5(2):231-7. doi:10.3922/j.psns.2012.2.14

28. Tomchek SD, Dunn W. Sensory processing in children with and without autism: a comparative study using the short sensory profile. Am J Occup Ther (2007) 61(2):190-200. doi:10.5014/ajot.61.2.190

29. Nyström P, Gredebäck G, Bölte S, Falck-Ytter T, EASE team. Hypersensitive pupillary light reflex in infants at risk for autism. Mol Autism (2015) 6(1):10. doi:10.1186/s13229-015-0011-6

30. Baranek GT, Berkson G. Tactile defensiveness in children with developmental disabilities: responsiveness and habituation. J Autism Dev Disord (1994) 24(4):457-71. doi:10.1007/BF02172128

31. Blakemore SJ, Tavassoli T, Calò S, Thomas RM, Catmur C, Frith U, et al. Tactile sensitivity in Asperger syndrome. Brain Cogn (2006) 61(1):5-13. doi:10.1016/j.bandc.2005.12.013

32. Paton B, Hohwy J, Enticott PG. The rubber hand illusion reveals proprioceptive and sensorimotor differences in autism spectrum disorders. J Autism Dev Disord (2012) 42(9):1870-83. doi:10.1007/s10803-011-1430-7

33. Tavassoli T, Miller LJ, Schoen SA, Nielsen DM, Baron-Cohen S. Sensory over-responsivity in adults with autism spectrum conditions. Autism (2013) 18(4):428-32. doi:10.1177/1362361313477246

34. Rosenhall U, Nordin V, Sandström M, Ahlsen G, Gillberg C. Autism and hearing loss. J Autism Dev Disord (1999) 29(5): 349-57.

35. Takahashi $\mathrm{H}$, Nakahachi $\mathrm{T}$, Komatsu S, Ogino $\mathrm{K}$, Iida $\mathrm{Y}$, Kamio $\mathrm{Y}$. Hyperreactivity to weak acoustic stimuli and prolonged acoustic startle latency in children with autism spectrum disorders. Mol Autism (2014) 5(1):23. doi:10.1186/2040-2392-5-23 
36. Madsen GF, Bilenberg N, Cantio C, Oranje B. Increased prepulse inhibition and sensitization of the startle reflex in autistic children. Autism Res (2014) 7(1):94-103. doi:10.1002/aur.1337

37. Ashwin C, Chapman E, Howells J, Rhydderch D, Walker I, Baron-Cohen S. Enhanced olfactory sensitivity in autism spectrum conditions. Mol Autism (2014) 5(1):53. doi:10.1186/2040-2392-5-53

38. Bennetto L, Kuschner ES, Hyman SL. Olfaction and taste processing in autism. Biol Psychiatry (2007) 62(9):1015-21. doi:10.1016/j.biopsych.2007.04.019

39. Suzuki Y, Critchley HD, Rowe A, Howlin P, Murphy DG. Impaired olfactory identification in Asperger's syndrome. J Neuropsychiatry Clin Neurosci (2003) 15(1):105-7. doi:10.1176/jnp.15.1.105

40. Remington AM, Swettenham JG, Lavie N. Lightening the load: perceptual load impairs visual detection in typical adults but not in autism. J Abnorm Psychol (2012) 121(2):544. doi:10.1037/a0027670

41. Masterton BA, Biederman GB. Proprioceptive versus visual control in autistic children. J Autism Dev Disord (1983) 13(2):141-52. doi:10.1007/ BF01531815

42. Blanche EI, Reinoso G, Chang MC, Bodison S. Proprioceptive processing difficulties among children with autism spectrum disorders and developmental disabilities. Am J Occup Ther (2012) 66(5):621-4. doi:10.5014/ ajot.2012.004234

43. Kéïta L, Mottron L, Bertone A. Far visual acuity is unremarkable in autism: do we need to focus on crowding? Autism Res (2010) 3(6):333-41. doi:10.1002/ aur.164

44. Bölte S, Schlitt S, Gapp V, Hainz D, Schirman S, Poustka F, et al. A close eye on the eagle-eyed visual acuity hypothesis of autism. J Autism Dev Disord (2012) 42(5):726-33. doi:10.1007/s10803-011-1300-3

45. Tavassoli T, Latham K, Bach M, Dakin SC, Baron-Cohen S. Psychophysical measures of visual acuity in autism spectrum conditions. Vision Res (2011) 51(15):1778-80. doi:10.1016/j.visres.2011.06.004

46. Jolliffe T, Baron-Cohen S. Are people with autism and Asperger syndrome faster than normal on the embedded figures test? J Child Psychol Psychiatry (1997) 38(5):527-34. doi:10.1111/j.1469-7610.1997.tb01539.x

47. O'Riordan MA, Plaisted KC, Driver J, Baron-Cohen S. Superior visual search in autism. J Exp Psychol Hum Percept Perform (2001) 27(3):719. doi:10.1037/0096-1523.27.3.719

48. O'Riordan M, Plaisted K. Enhanced discrimination in autism. Q J Exp Psychol A (2001) 54(4):961-79. doi:10.1080/713756000

49. Smith H, Milne E. Reduced change blindness suggests enhanced attention to detail in individuals with autism. JChild Psychol Psychiatry (2009) 50(3):300-6. doi:10.1111/j.1469-7610.2008.01957.x

50. Mottron L, Peretz I, Belleville S, Rouleau N. Absolute pitch in autism: a case study. Neurocase (1999) 5(6):485-501. doi:10.1093/neucas/5.6.501

51. Mottron L, Dawson M, Soulieres I, Hubert B, Burack J. Enhanced perceptual functioning in autism: an update, and eight principles of autistic perception. J Autism Dev Disord (2006) 36(1):27-43. doi:10.1007/s10803-005-0040-7

52. Koldewyn K, Whitney D, Rivera SM. The psychophysics of visual motion and global form processing in autism. Brain (2009) 133(Pt 2):599-610. doi:10.1093/brain/awp272

53. Simmons DR, Robertson AE, McKay LS, Toal E, McAleer P, Pollick FE. Vision in autism spectrum disorders. Vision Res (2009) 49(22):2705-39. doi:10.1016/j.visres.2009.08.005

54. Spencer J, O’Brien J, Riggs K, Braddick O, Atkinson J, Wattam-Bell J. Motion processing in autism: evidence for a dorsal stream deficiency. Neuroreport (2000) 11(12):2765-7. doi:10.1097/00001756-200008210-00031

55. Koldewyn K, Whitney D, Rivera SM. Neural correlates of coherent and biological motion perception in autism. Dev Sci (2011) 14(5):1075-88. doi:10.1111/j.1467-7687.2011.01058.x

56. McCleery JP, Allman E, Carver LJ, Dobkins KR. Abnormal magnocellular pathway visual processing in infants at risk for autism. Biol Psychiatry (2007) 62(9):1007-14. doi:10.1016/j.biopsych.2007.02.009

57. Pellicano E, Gibson L, Maybery M, Durkin K, Badcock DR. Abnormal global processing along the dorsal visual pathway in autism: a possible mechanism for weak visuospatial coherence? Neuropsychologia (2005) 43(7):1044-53. doi:10.1016/j.neuropsychologia.2004.10.003

58. Bertone A, Mottron L, Jelenic P, Faubert J. Enhanced and diminished visuo-spatial information processing in autism depends on stimulus complexity. Brain (2005) 128(10):2430-41. doi:10.1093/brain/awh561
59. Bonnel A, Mottron L, Peretz I, Trudel M, Gallun E, Bonnel AM. Enhanced pitch sensitivity in individuals with autism: a signal detection analysis. J Cogn Neurosci (2003) 15(2):226-35. doi:10.1162/089892903321208169

60. Heaton P, Hudry K, Ludlow A, Hill E. Superior discrimination of speech pitch and its relationship to verbal ability in autism spectrum disorders. Cogn Neuropsychol (2008) 25(6):771-82. doi:10.1080/02643290802336277

61. O’Riordan M, Passetti F. Discrimination in autism within different sensory modalities. J Autism Dev Disord (2006) 36(5):665-75. doi:10.1007/ s10803-006-0106-1

62. Järvinen-Pasley A, Wallace GL, Ramus F, Happé F, Heaton P. Enhanced perceptual processing of speech in autism. Dev Sci (2008) 11(1):109-21. doi:10.1111/j.1467-7687.2007.00644.x

63. Alcántara JI, Weisblatt EJ, Moore BC, Bolton PF. Speech-in-noise perception in high-functioning individuals with autism or Asperger's syndrome. J Child Psychol Psychiatry (2004) 45(6):1107-14. doi:10.1111/j.1469-7610.2004. t01-1-00303.x

64. Teder-Sälejärvi WA, Pierce KL, Courchesne E, Hillyard SA. Auditory spatial localization and attention deficits in autistic adults. Brain Res Cogn Brain Res (2005) 23(2):221-34. doi:10.1016/j.cogbrainres.2004.10.021

65. Cascio C, McGlone F, Folger S, Tannan V, Baranek G, Pelphrey KA, et al. Tactile perception in adults with autism: a multidimensional psychophysical study. J Autism Dev Disord (2008) 38(1):127-37. doi:10.1007/s10803-007-0370-8

66. Tommerdahl M, Tannan V, Cascio CJ, Baranek GT, Whitsel BL. Vibrotactile adaptation fails to enhance spatial localization in adults with autism. Brain Res (2007) 1154:116-23. doi:10.1016/j.brainres.2007.04.032

67. Puts NA, Wodka EL, Tommerdahl M, Mostofsky SH, Edden RA. Impaired tactile processing in children with autism spectrum disorder. J Neurophysiol (2014) 111(9):1803-11. doi:10.1152/jn.00890.2013

68. Tavassoli T, Baron-Cohen S. Olfactory detection thresholds and adaptation in adults with autism spectrum condition. JAutism Dev Disord (2012) 42(6):905-9. doi:10.1007/s10803-011-1321-y

69. Brown C, Tollefson N, Dunn W, Cromwell R, Filion D. The adult sensory profile: measuring patterns of sensory processing. Am J Occup Ther (2001) 55(1):75-82. doi:10.5014/ajot.55.1.75

70. Crane L, Goddard L, Pring L. Sensory processing in adults with autism spectrum disorders. Autism (2009) 13(3):215-28. doi:10.1177/1362361309103794

71. Kientz MA, Dunn W. A comparison of the performance of children with and without autism on the sensory profile. Am J Occup Ther (1997) 51(7):530-7. doi:10.5014/ajot.51.7.530

72. Leekam SR, Nieto C, Libby SJ, Wing L, Gould J. Describing the sensory abnormalities of children and adults with autism. J Autism Dev Disord (2007) 37(5):894-910. doi:10.1007/s10803-006-0218-7

73. Schoen SA, Miller LJ, Brett-Green BA, Nielsen DM. Physiological and behavioral differences in sensory processing: a comparison of children with autism spectrum disorder and sensory modulation disorder. Front Integr Neurosci (2009) 3:29. doi:10.3389/neuro.07.029.2009

74. Kern JK, Trivedi MH, Grannemann BD, Garver CR, Johnson DG, Andrews AA, et al. Sensory correlations in autism. Autism (2007) 11(2):123-34. doi:10.1177/1362361307075702

75. Baron-Cohen S, Johnson D, Asher J, Wheelwright S, Fisher SE, Gregersen PK, et al. Is synaesthesia more common in autism? Mol Autism (2013) 4(1):40. doi:10.1186/2040-2392-4-40

76. Stevenson RA, Siemann JK, Woynaroski TG, Schneider BC, Eberly HE, Camarata SM, et al. Evidence for diminished multisensory integration in autism spectrum disorders. J Autism Dev Disord (2014) 44(12):3161-7. doi:10.1007/s10803-014-2179-6

77. Stein BE, Stanford TR, Rowland BA. The neural basis of multisensory integration in the midbrain: its organization and maturation. Hear Res (2009) 258(1):4-15. doi:10.1016/j.heares.2009.03.012

78. Kern JK, Trivedi MH, Garver CR, Grannemann BD, Andrews AA, Savla JS, et al. The pattern of sensory processing abnormalities in autism. Autism (2006) 10(5):480-94. doi:10.1177/1362361306066564

79. Ben-Sasson A, Hen L, Fluss R, Cermak SA, Engel-Yeger B, Gal E. A meta-analysis of sensory modulation symptoms in individuals with autism spectrum disorders. J Autism Dev Disord (2009) 39(1):1-11. doi:10.1007/ s10803-008-0593-3

80. Mostofsky SH, Dubey P, Jerath VK, Jansiewicz EM, Goldberg MC, Denckla MB. Developmental dyspraxia is not limited to imitation in 
children with autism spectrum disorders. JInt Neuropsychol Soc (2006) 12(03):314-26. doi:10.1017/S1355617706060437

81. Cummins A, Piek JP, Dyck MJ. Motor coordination, empathy, and social behaviour in school-aged children. Dev Med Child Neurol (2005) 47(7):43742. doi:10.1017/S001216220500085X

82. Ghaziuddin M, Butler E. Clumsiness in autism and Asperger syndrome: a further report. JIntellect Disabil Res (1998) 42(1):43-8. doi:10.1046/j.1365-2788.1998.00065.x

83. Jansiewicz EM, Goldberg MC, Newschaffer CJ, Denckla MB, Landa R, Mostofsky SH. Motor signs distinguish children with high functioning autism and Asperger's syndrome from controls. J Autism Dev Disord (2006) 36(5):613-21. doi:10.1007/s10803-006-0109-y

84. Dziuk MA, Larson JC, Apostu A, Mahone EM, Denckla MB, Mostofsky SH. Dyspraxia in autism: association with motor, social, and communicative deficits. Dev Med Child Neurol (2007) 49(10):734-9. doi:10.1111/ j.1469-8749.2007.00734.x

85. Hilton C, Graver K, LaVesser P. Relationship between social competence and sensory processing in children with high functioning autism spectrum disorders. Res Autism Spectr Disord (2007) 1(2):164-73. doi:10.1016/j. rasd.2006.10.002

86. MacDonald M, Lord C, Ulrich D. The relationship of motor skills and adaptive behavior skills in young children with autism spectrum disorders. Res Autism Spectr Disord (2013) 7(11):1383-90. doi:10.1016/j.rasd.2013.07.020

87. Hilton C, Wente L, LaVesser P, Ito M, Reed C, Herzberg G. Relationship between motor skill impairment and severity in children with Asperger syndrome. Res Autism Spectr Disord (2007) 1(4):339-49. doi:10.1016/j. rasd.2006.12.003

88. Piek JP, Dyck MJ. Sensory-motor deficits in children with developmental coordination disorder, attention deficit hyperactivity disorder and autistic disorder. Hum Mov Sci (2004) 23(3):475-88. doi:10.1016/j.humov.2004.08.019

89. Leary MR, Hill DA. Moving on: autism and movement disturbance. Ment Retard (1996) 34(1):39-53.

90. Landa R, Garrett-Mayer E. Development in infants with autism spectrum disorders: a prospective study. J Child Psychol Psychiatry (2006) 47(6):629-38. doi:10.1111/j.1469-7610.2006.01531.x

91. Mostofsky SH, Burgess MP, Larson JCG. Increased motor cortex white matter volume predicts motor impairment in autism. Brain (2007) 130(8):2117-22. doi:10.1093/brain/awm129

92. Dewey D, Cantell M, Crawford SG. Motor and gestural performance in children with autism spectrum disorders, developmental coordination disorder, and/or attention deficit hyperactivity disorder. J Int Neuropsychol Soc (2007) 13(02):246-56. doi:10.1017/S1355617707070270

93. Matsushima K, Kato T. Social interaction and atypical sensory processing in children with autism spectrum disorders. Hong Kong J Occup Ther (2013) 23(2):89-96. doi:10.1016/j.hkjot.2013.11.003

94. Reynolds S, Bendixen R, Lawrence T, Lane S. A pilot study examining activity participation, sensory responsiveness, and competence in children with high functioning autism spectrum disorder. J Autism Dev Disord (2011) 41:1496-506. doi:10.1007/s10803-010-1173-x

95. Fitzgibbon BM, Segrave RA, Fitzgerald PB, Enticott PG. Can studies of pain help to bridge the gap between sensory and social impairments in autism? Front Hum Neurosci (2013) 7:103. doi:10.3389/fnhum.2013.00103

96. Boyd BA, Baranek GT, Sideris J, Poe MD, Watson LR, Patten E, et al. Sensory features and repetitive behaviors in children with autism and developmental delays. Autism Res (2010) 3(2):78-87. doi:10.1002/aur.124

97. Lane AE, Young RL, Baker AE, Angley MT. Sensory processing subtypes in autism: association with adaptive behavior. J Autism Dev Disord (2010) 40(1):112-22. doi:10.1007/s10803-009-0840-2

98. Siaperas P, Ring HA, McAllister CJ, Henderson S, Barnett A, Watson P, et al. Atypical movement performance and sensory integration in Asperger's syndrome. J Autism Dev Disord (2012) 42(5):718-25. doi:10.1007/s10803-011$1301-2$

99. Tavassoli T, Hoekstra RA, Baron-Cohen S. The sensory perception quotient (SPQ): development and validation of a new sensory questionnaire for adults with and without autism. Mol Autism (2014) 5(1):29. doi:10.1186/2040-2392-5-29

100. Brisson J, Warreyn P, Serres J, Foussier S, Adrien JL. Motor anticipation failure in infants with autism: a retrospective analysis of feeding situations. Autism (2012) 16(4):420-9. doi:10.1177/1362361311423385
101. Machado S, Cunha M, Velasques B, Minc D, Teixeira S, Domingues CA, et al. Sensorimotor integration: basic concepts, abnormalities related to movement disorders and sensorimotor training-induced cortical reorganization. Rev Neurol (2010) 51(7):427-36.

102. Milne E, White S, Campbell R, Swettenham J, Hansen P, Ramus F. Motion and form coherence detection in autistic spectrum disorder: relationship to motor control and 2: 4 digit ratio. J Autism Dev Disord (2006) 36(2):225-37. doi:10.1007/s10803-005-0052-3

103. Gowen E, Miall RC. Behavioural aspects of cerebellar function in adults with Asperger syndrome. Cerebellum (2005) 4(4):279-89. doi:10.1080/ 14734220500355332

104. Iwanaga R, Kawasaki C, Tsuchida R. Brief report: comparison of sensorymotor and cognitive function between autism and Asperger syndrome in preschool children. J Autism Dev Disord (2000) 30(2):169-74. doi:10.102 3/A:1005467807937

105. Brooks VB. Motor control how posture and movements are governed. Phys Ther (1983) 63(5):664-73.

106. Todorov E, Jordan MI. Optimal feedback control as a theory of motor coordination. Nat Neurosci (2002) 5(11):1226-35. doi:10.1038/nn963

107. Wolpert DM, Flanagan JR. Motor prediction. Curr Biol (2001) 11(18):R729_ 32. doi:10.1016/S0960-9822(01)00432-8

108. Cattaneo L, Fabbri-Destro M, Boria S, Pieraccini C, Monti A, Cossu G, et al. Impairment of actions chains in autism and its possible role in intention understanding. Proc Natl Acad Sci U S A (2007) 104(45):17825-30. doi:10.1073/pnas.0706273104

109. Dowd AM, McGinley JL, Taffe JR, Rinehart NJ. Do planning and visual integration difficulties underpin motor dysfunction in autism? A kinematic study of young children with autism. J Autism Dev Disord (2012) 42(8):1539-48. doi:10.1007/s10803-011-1385-8

110. Rinehart NJ, Bellgrove MA, Tonge BJ, Brereton AV, Howells-Rankin D, Bradshaw JL. An examination of movement kinematics in young people with high-functioning autism and Asperger's disorder: further evidence for a motor planning deficit. J Autism Dev Disord (2006) 36(6):757-67. doi:10.1007/s10803-006-0118-x

111. Whyatt C, Craig C. Sensory-motor problems in autism. Front Integr Neurosci (2013) 7:51. doi:10.3389/fnint.2013.00051

112. Fabbri-Destro M, Cattaneo L, Boria S, Rizzolatti G. Planning actions in autism. Exp Brain Res (2009) 192(3):521-5. doi:10.1007/s00221-008-1578-3

113. Ronconi L, Gori S, Ruffino M, Molteni M, Facoetti A. Zoom-out attentional impairment in children with autism spectrum disorder. Cortex (2013) 49(4):1025-33. doi:10.1016/j.cortex.2012.03.005

114. Schmitt LM, Cook EH, Sweeney JA, Mosconi MW. Saccadic eye movement abnormalities in autism spectrum disorder indicate dysfunctions in cerebellum and brainstem. Mol Autism (2014) 5(1):47. doi:10.1186/2040-2392-5-47

115. Mosconi MW, Luna B, Kay-Stacey M, Nowinski CV, Rubin LH, Scudder C, et al. Saccade adaptation abnormalities implicate dysfunction of cerebellardependent learning mechanisms in autism spectrum disorders (ASD). PLoS One (2013) 8(5):e63709. doi:10.1371/journal.pone.0063709

116. Wilkes BJ, Carson TB, Patel KP, Lewis MH, White KD. Oculomotor performance in children with high-functioning autism spectrum disorders. Res Dev Disabil (2015) 38:338-44. doi:10.1016/j.ridd.2014.12.022

117. Price KJ, Edgell D, Kerns KA. Timing deficits are implicated in motor dysfunction in Asperger's syndrome. Res Autism Spectr Disord (2012) 6(2):857-60. doi:10.1016/j.rasd.2011.11.007

118. Glazebrook C, Gonzalez D, Hansen S, Elliott D. The role of vision for online control of manual aiming movements in persons with autism spectrum disorders. Autism (2009) 13(4):411-33. doi:10.1177/1362361309105659

119. Freeth M, Chapman P, Ropar D, Mitchell P. Do gaze cues in complex scenes capture and direct the attention of high functioning adolescents with ASD? Evidence from eye-tracking. JAutism Dev Disord (2010) 40(5):534-47. doi:10.1007/s10803-009-0893-2

120. Freeth M, Ropar D, Chapman P, Mitchell P. The eye gaze direction of an observed person can bias perception, memory, and attention in adolescents with and without autism spectrum disorder. JExp Child Psychol (2010) 105(1):20-37. doi:10.1016/j.jecp.2009.10.001

121. Fletcher-Watson S, Leekam SR, Benson V, Frank MC, Findlay JM. Eye-movements reveal attention to social information in autism spectrum disorder. Neuropsychologia (2009) 47(1):248-57. doi:10.1016/j. neuropsychologia.2008.07.016 
122. Cassidy S, Ropar D, Mitchell P, Chapman P. Can adults with autism spectrum disorders infer what happened to someone from their emotional response? Autism Res (2014) 7(1):112-23. doi:10.1002/aur.1351

123. Cassidy S, Mitchell P, Chapman P, Ropar D. Processing of spontaneous emotional responses in adolescents and adults with autism spectrum disorders: effect of stimulus type. Autism Res (2015) 8(5):534-44. doi:10.1002/ aur.1468

124. Klin A, Jones W, Schultz R, Volkmar F. The enactive mind, or from actions to cognition: lessons from autism. Philos Trans R Soc Lond B Biol Sci (2003) 358(1430):345-60. doi:10.1098/rstb.2002.1202

125. Speer LL, Cook AE, McMahon WM, Clark E. Face processing in children with autism effects of stimulus contents and type. Autism (2007) 11(3):265-77. doi:10.1177/1362361307076925

126. Pillai D, Sheppard E, Mitchell P. Can people guess what happened to others from their reactions? PLoS One (2012) 7(11):e49859. doi:10.1371/journal. pone.0049859

127. Pillai D, Sheppard E, Ropar D, Marsh L, Pearson A, Mitchell P. Using other minds as a window onto the world: guessing what happened from clues in behaviour. J Autism Dev Disord (2014) 44(10):2430-9. doi:10.1007/ s10803-014-2106-x

128. Gepner B, Mestre DR. Brief report: postural reactivity to fast visual motion differentiates autistic from children with Asperger syndrome. J Autism Dev Disord (2002) 32(3):231-8. doi:10.1023/A:1015410015859

129. Marko MK, Crocetti D, Hulst T, Donchin O, Shadmehr R, Mostofsky SH. Behavioural and neural basis of anomalous motor learning in children with autism. Brain (2015) 138(Pt 3):784-97. doi:10.1093/brain/awu394

130. Izawa J, Pekny SE, Marko MK, Haswell CC, Shadmehr R, Mostofsky SH. Motor learning relies on integrated sensory inputs in ADHD, but over-selectively on proprioception in autism spectrum conditions. Autism Res (2012) 5(2):124-36. doi:10.1002/aur.1222

131. Schmitz C, Martineau J, Barthélémy C, Assaiante C. Motor control and children with autism: deficit of anticipatory function? Neurosci Lett (2003) 348(1):17-20. doi:10.1016/S0304-3940(03)00644-X

132. Gowen E, Stanley J, Miall RC. Movement interference in autism-spectrum disorder. Neuropsychologia (2008) 46(4):1060-8. doi:10.1016/j. neuropsychologia.2007.11.004

133. Salowitz NM, Eccarius P, Karst J, Carson A, Schohl K, Stevens S, et al. Brief report: visuo-spatial guidance of movement during gesture imitation and mirror drawing in children with autism spectrum disorders. J Autism Dev Disord (2013) 43(4):985-95. doi:10.1007/s10803-012-1631-8

134. Vandenbroucke MW, Steven Scholte H, Engeland HV, Lamme VA, Kemner C. A new approach to the study of detail perception in autism spectrum disorder (ASD): investigating visual feedforward, horizontal and feedback processing. Vision Res (2009) 49(9):1006-16. doi:10.1016/j.visres.2007.12.017

135. Larson JCG, Bastian AJ, Donchin O, Shadmehr R, Mostofsky SH. Acquisition of internal models of motor tasks in children with autism. Brain (2008) 131(11):2894-903. doi:10.1093/brain/awn226

136. Rinehart NJ, Bradshaw JL, Brereton AV, Tonge BJ. Movement preparation in high-functioning autism and Asperger disorder: a serial choice reaction time task involving motor reprogramming. JAutism Dev Disord (2001) 31(1):79-88. doi:10.1023/A:1005617831035

137. Nazarali N, Glazebrook CM, Elliott D. Movement planning and reprogramming in individuals with autism. J Autism Dev Disord (2009) 39(10):1401-11. doi:10.1007/s10803-009-0756-x

138. Pierce K, Courchesne E. Evidence for a cerebellar role in reduced exploration and stereotyped behavior in autism. Biol Psychiatry (2001) 49(8):655-64. doi:10.1016/S0006-3223(00)01008-8

139. Glickstein M. Cerebellum and the sensory guidance of movement. Novartis Found Symp (1998) 218:252-66.

140. Paulin MG. The role of the cerebellum in motor control and perception. Brain Behav Evol (1993) 41(1):39-50. doi:10.1159/000113822

141. Stoodley CJ, Schmahmann JD. Functional topography in the human cerebellum: a meta-analysis of neuroimaging studies. Neuroimage (2009) 44(2):489-501. doi:10.1016/j.neuroimage.2008.08.039

142. Kawato M, Kuroda T, Imamizu H, Nakano E, Miyauchi S, Yoshioka T. Internal forward models in the cerebellum: fMRI study on grip force and load force coupling. Prog Brain Res (2003) 142:171-88. doi:10.1016/ S0079-6123(03)42013-X
143. Mostofsky SH, Goldberg MC, Landa RJ, Denckla MB. Evidence for a deficit in procedural learning in children and adolescents with autism: implications for cerebellar contribution. J Int Neuropsychol Soc (2000) 6(07):752-9. doi:10.1017/S1355617700677020

144. Fuentes CT, Bastian AJ. 'Motor cognition' - what is it and is the cerebellum involved? Cerebellum (2007) 6(3):232-6. doi:10.1080/14734220701329268

145. Fatemi SH, Aldinger KA, Ashwood P, Bauman ML, Blaha CD, Blatt GJ, et al. Consensus paper: pathological role of the cerebellum in autism. Cerebellum (2012) 11(3):777-807. doi:10.1007/s12311-012-0355-9

146. McAlonan GM, Daly E, Kumari V, Critchley HD, van Amelsvoort T, Suckling J, et al. Brain anatomy and sensorimotor gating in Asperger's syndrome. Brain (2002) 125(7):1594-606. doi:10.1093/brain/awf150

147. Allen G, Müller RA, Courchesne E. Cerebellar function in autism: functional magnetic resonance image activation during a simple motor task. Biol Psychiatry (2004) 56(4):269-78. doi:10.1016/j.biopsych.2004.06.005

148. Müller RA, Pierce K, Ambrose JB, Allen G, Courchesne E. Atypical patterns of cerebral motor activation in autism: a functional magnetic resonance study. Biol Psychiatry (2001) 49(8):665-76. doi:10.1016/S0006-3223(00)01004-0

149. Allen G, Courchesne E. Differential effects of developmental cerebellar abnormality on cognitive and motor functions in the cerebellum: an fMRI study of autism. Am J Psychiatry (2003) 160(2):262-73. doi:10.1176/appi. ajp.160.2.262

150. Bauman ML, Kemper TL. Structural brain anatomy in autism: what is the evidence. Neurobiol Autism (2005) 2:121-35.

151. Amaral DG, Schumann CM, Nordahl CW. Neuroanatomy of autism. Trends Neurosci (2008) 31(3):137-45. doi:10.1016/j.tins.2007.12.005

152. Chukoskie L, Townsend J, Westerfield M. Motor skill in autism spectrum disorders: a subcortical view. Int Rev Neurobiol (2013) 113(7):207-49. doi:10.1016/B978-0-12-418700-9.00007-1

153. Nagy A, Eördegh G, Paróczy Z, Márkus Z, Benedek G. Multisensory integration in the basal ganglia. Eur J Neurosci (2006) 24(3):917-24. doi:10.1111/ j.1460-9568.2006.04942.x

154. Calabresi P, Picconi B, Tozzi A, Ghiglieri V, Di Filippo M. Direct and indirect pathways of basal ganglia: a critical reappraisal. Nat Neurosci (2014) 17(8):1022-30. doi:10.1038/nn.3743

155. Fuccillo MV. Striatal circuits as a common node for autism pathophysiology. Front Neurosci (2016) 10:27. doi:10.3389/fnins.2016.00027

156. Estes A, Shaw DW, Sparks BF, Friedman S, Giedd JN, Dawson G, et al. Basal ganglia morphometry and repetitive behavior in young children with autism spectrum disorder. Autism Res (2011) 4(3):212-20. doi:10.1002/aur.193

157. Di Martino A, Kelly C, Grzadzinski R, Zuo XN, Mennes M, Mairena MA, et al. Aberrant striatal functional connectivity in children with autism. Biol Psychiatry (2011) 69(9):847-56. doi:10.1016/j.biopsych.2010.10.029

158. Voogd J, Glickstein M. The anatomy of the cerebellum. Trends Cogn Sci (1998) 2(9):307-13. doi:10.1016/S1364-6613(98)01210-8

159. Yager LM, Garcia AF, Wunsch AM, Ferguson SM. The ins and outs of the striatum: role in drug addiction. Neuroscience (2015) 301:529-41. doi:10.1016/j. neuroscience.2015.06.033

160. Puts NA, Edden RA, Evans CJ, McGlone F, McGonigle DJ. Regionally specific human GABA concentration correlates with tactile discrimination thresholds J Neurosci (2011) 31(46):16556-60. doi:10.1523/JNEUROSCI.4489-11.2011

161. Purves D, Augustine GJ, Fitzpatrick D, Katz LC, LaMantia AS, McNamara JO, et al. Excitatory and inhibitory postsynaptic potentials. Neuroscience. 2 nd ed. Sunderland, MA: Sinauer Associates (2001).

162. Balemans MGM, Mans D, Smith I, Van Benthem J. The influence of GABA on the synthesis of $\mathrm{N}$-acetylserotonin, melatonin, $\mathrm{O}$-acetyl-5-hydroxytryptophol and O-acetyl-5-methoxytryptophol in the pineal gland of the male Wistar rat. Reprod Nutr Dev (1983) 23(1):151-60. doi:10.1051/rnd:19830114

163. Petty F. GABA and mood disorders: a brief review and hypothesis. J Affect Disord (1995) 34(4):275-81. doi:10.1016/0165-0327(95)00025-I

164. Hensch TK, Fagiolini M, Mataga N, Stryker MP, Baekkeskov S, Kash SF. Local GABA circuit control of experience-dependent plasticity in developing visual cortex. Science (1998) 282(5393):1504-8. doi:10.1126/science.282. 5393.1504

165. Gaetz W, Bloy L, Wang DJ, Port RG, Blaskey L, Levy SE, et al. GABA estimation in the brains of children on the autism spectrum: measurement precision and regional cortical variation. Neuroimage (2014) 86:1-9. doi:10.1016/j. neuroimage.2013.05.068 
166. DeLorey TM,SahbaieP,Hashemi E,LiWW,Salehi A, ClarkDJ. Somatosensory and sensorimotor consequences associated with the heterozygous disruption of the autism candidate gene, Gabrb3. Behav Brain Res (2011) 216(1):36-45. doi:10.1016/j.bbr.2010.06.032

167. Tavassoli T, Auyeung B, Murphy LC, Baron-Cohen S, Chakrabarti B. Variation in the autism candidate gene GABRB3 modulates tactile sensitivity in typically developing children. Mol Autism (2012) 3(1):6-6. doi:10.1186/2040-2392-3-6

168. Fatemi SH, Reutiman TJ, Folsom TD, Thuras PD. GABAA receptor downregulation in brains of subjects with autism. J Autism Dev Disord (2009) 39(2):223-30. doi:10.1007/s10803-008-0646-7

169. Fatemi SH, Halt AR, Stary JM, Kanodia R, Schulz SC, Realmuto GR. Glutamic acid decarboxylase 65 and $67 \mathrm{kDa}$ proteins are reduced in autistic parietal and cerebellar cortices. Biol Psychiatry (2002) 52(8):805-10. doi:10.1016/ S0006-3223(02)01430-0

170. Hassan TH, Abdelrahman HM, Abdel Fattah NR, El-Masry NM, Hashim HM, El-Gerby KM, et al. Blood and brain glutamate levels in children with autistic disorder. Res Autism Spectr Disord (2013) 7(4):541-8. doi:10.1016/j. rasd.2012.12.005

171. Buxbaum JD, Silverman JM, Smith CJ, Greenberg DA, Kilifarski M, Reichert J, et al. Association between a GABRB3 polymorphism and autism. Mol Psychiatry (2002) 7(3):311-6. doi:10.1038/sj.mp.4001011

172. Pizzarelli R, Cherubini E. Alterations of GABAergic signaling in autism spectrum disorders. Neural Plast (2011) 2011:297153. doi:10.1155/2011/297153

173. Green SA, Hernandez L, Tottenham N, Krasileva K, Bookheimer SY, Dapretto M. Neurobiology of sensory overresponsivity in youth with autism spectrum disorders. JAMA Psychiatry (2015) 72(8):778-86. doi:10.1001/ jamapsychiatry.2015.0737

174. Moller AR. Hearing: Anatomy, Physiology, and Disorders of the Auditory System. San Diego, CA: Academic Press (2006).

175. Banji D, Banji OJ, Abbagoni S, Hayath MS, Kambam S, Chiluka VL. Amelioration of behavioral aberrations and oxidative markers by green tea extract in valproate induced autism in animals. Brain Res (2011) 1410:141-51. doi:10.1016/j.brainres.2011.06.063

176. Kimura K, Ozeki M, Juneja LR, Ohira H. L-Theanine reduces psychological and physiological stress responses. Biol Psychol (2007) 74(1):39-45. doi:10.1016/j.biopsycho.2006.06.006

177. Yamada T, Terashima T, Kawano S, Furuno R, Okubo T, Juneja LR, et al. Theanine, $\gamma$-glutamylethylamide, a unique amino acid in tea leaves, modulates neurotransmitter concentrations in the brain striatum interstitium in conscious rats. Amino Acids (2009) 36(1):21-7. doi:10.1007/s00726-007-0020-7
178. Ritsner MS, Miodownik C, Ratner Y, Shleifer T, Mar M, Pintov L, et al. L-theanine relieves positive, activation, and anxiety symptoms in patients with schizophrenia and schizoaffective disorder: an 8-week, randomized, double-blind, placebo-controlled, 2-center study. J Clin Psychiatry (2011) 72(1):34-42. doi:10.4088/JCP.09m05324gre

179. Nathan PJ, Lu K, Gray M, Oliver C. The neuropharmacology of L-theanine (N-ethyl-L-glutamine) a possible neuroprotective and cognitive enhancing agent. J Herb Pharmacother (2006) 6(2):21-30. doi:10.1080/ J157v06n02_02

180. Osterling J, Dawson G. Early recognition of children with autism: a study of first birthday home videotapes. J Autism Dev Disord (1994) 24(3):247-57. doi:10.1007/BF02172225

181. Osterling JA, Dawson G, Munson JA. Early recognition of 1-year-old infants with autism spectrum disorder versus mental retardation. Dev Psychopathol (2002) 14(02):239-51. doi:10.1017/S0954579402002031

182. Marsh L, Pearson A, Ropar D, Hamilton A. Children with autism do not overimitate. Curr Biol (2013) 23(7):R266-8. doi:10.1016/j.cub.2013.02.036

183. Skewes JC, Skewes L, Roepstorff A, Frith CD. Doing what others see: visuomotor conversion to informational social influence. J Exp Psychol Hum Percept Perform (2013) 39(5):1291. doi:10.1037/a0031572

184. Hoke KL, Ryan MJ, Wilczynski W. Integration of sensory and motor processing underlying social behaviour in túngara frogs. Proc Biol Sci (2007) 274(1610):641-9. doi:10.1098/rspb.2006.0038

185. Baron-Cohen S, Leslie AM, Frith U. Does the autistic child have a "theory of mind"? Cognition (1985) 21(1):37-46. doi:10.1016/0010-0277(85) 90022-8

186. Senju A, Johnson MH. Atypical eye contact in autism: models, mechanisms and development. Neurosci Biobehav Rev (2009) 33(8):1204-14. doi:10.1016/j. neubiorev.2009.06.001

187. Piaget J. Piaget's Theory. Berlin: Springer (1976). p. 11-23.

Conflict of Interest Statement: The authors declare that the research was conducted in the absence of any commercial or financial relationships that could be construed as a potential conflict of interest.

Copyright (c) 2016 Hannant, Tavassoli and Cassidy. This is an open-access article distributed under the terms of the Creative Commons Attribution License (CC $B Y)$. The use, distribution or reproduction in other forums is permitted, provided the original author(s) or licensor are credited and that the original publication in this journal is cited, in accordance with accepted academic practice. No use, distribution or reproduction is permitted which does not comply with these terms. 